\title{
“A DAMA PÉ-DE-CABRA”: ENTRE O HISTÓRICO E O FANTÁSTICO
}

Carla Carvalho Alves ${ }^{1}$

RESUMO: Helena Carvalhão Buescu, ao analisar o conto fantástico de Alexandre Herculano, "A Dama Pé-de-Cabra", orienta-se, entre outros parâmetros, pela relação entre predação e domesticidade, extraída da temática do caçador-caçado implicada na narrativa. Aproveitando as reflexões suscitadas pelo artigo de Buescu, principalmente no que se refere à questão da dimensão alegórica do conto e da temática da domesticidade aí ressaltada, buscaremos refletir também, de modo tangencial a essa proposta, sobre um aspecto relevante contido na estruturação narrativa: a alternância entre a periculosidade advinda do contexto interno, ou doméstico, e do externo, ou estrangeiro.

PALAVRAS-CHAVE: Alexandre Herculano; fantástico; histórico

\section{"A DAMA PÉ-DE-CABRA": BETWEEN THE HISTORICAL AND THE FANTASTIC}

ABSTRACT: Helena Carvalhão Buescu, when analyzing the fantastic tale by Alexandre Herculano "A Dama Pé-de-Cabra", is guided, among other parameters, by the relationship between predation and domesticity, extracted from the hunter-hunted theme implicated in the narrative. Considering the reflections raised by Buescu article, especially as regards the question of the allegorical dimension of the story and the theme of domesticity emphasized there, we seek also reflect tangentially to this proposal on a relevant aspect contained in the narrative structure: an alternation between the danger arising on the internal (or domestic) and the external (or foreign) contexts.

KEYWORDS: Alexandre Herculano; fantastic; historical

\footnotetext{
${ }^{1}$ Pesquisadora de pós-doutorado na Universidade de São Paulo (USP/FAPESP)
} 
Em 1851, Alexandre Herculano reuniu, em volume, diversos textos literários publicados entre os anos de 1838 e 1846, nas revistas O Panorama e A Ilustração, intitulando a coletânea de Lendas e narrativas. A maioria dos textos foi escrita anteriormente a Eurico, o presbitero, O monge de Cister e $O$ bobo. Ofélia Paiva Monteiro, como outros autores, diz que esses "contos e novelas históricos representaram para o escritor uma preparação para os seus romances" (MONTEIRO, s.d., p.27). O próprio Herculano, na “Advertência da primeira edição" de suas Lendas, diz que o mérito de tais textos e a razão da publicação em volume é, justamente, por se encontrar aí o marco inicial do romance histórico português:

Corrigindo-os e publicando-os de novo, para se ajuntarem a composições mais extensas e menos imperfeitas que já viram a luz pública em volumes separados, ele [o próprio Herculano] quis apenas preservar do esquecimento, a que por via de regra são condenados, mais cedo ou mais tarde, os escritos inseridos nas colunas das publicações periódicas, as primeiras tentativas do romance histórico que se fizeram na língua portuguesa. (HERCULANO, s.d., p.VI)

E, de fato, à exceção de "O pároco da aldeia" e do texto autobiográfico "De Jersey a Grandville”, encontramos nessas narrativas a prevalência da ambientação medieval, assim como, recortes de importantes fatos e lendas da história nacional.

Entre 1838 e 1839, Herculano publicou, na imprensa periódica, "O castelo de Faria", "O bispo negro", e "A abóbada”, posteriormente, de 1841 a 1842, o autor lançou, também aí, "Arras por foro de Espanha". "A Dama Pé-de-Cabra" saiu no Panorama em 1843, e, finalmente, foi publicado “O alcaide de Santarém”, entre 1845 e 1846 (CARDOSO, 2003, p.168). Mas, esses contos representam uma seleção feita inicialmente, ao que tudo indica, pelo próprio Herculano, ficando outras narrativas, do mesmo período e de anos anteriores, fora dessa primeira publicação em volume. A maioria dos contos, inclusive, constava nas páginas de O Panorama sem assinatura "dado o anonimato inicial da colaboração [de Herculano] dada à revista." (CARDOSO, 2003, p.168).

Margarida Cardoso levanta duas hipóteses para a exclusão de algumas narrativas em tal seleção realizada por Herculano: "ou porque o Escritor os julgasse esteticamente fracos, ou porque quisesse deixar cair no esquecimento textos 'reinvestidos' em obras de maior vulto (é o caso de "Destruição de Áuria", que parece representar um avatar incipiente de Eurico)" (CARDOSO, 2003, p.168).

Os contos apresentados nas Lendas e narrativas são considerados por diversos 
críticos como um trabalho, sobretudo, de pesquisa e recolha de lendas tradicionais, apresentando uma menor elaboração ficcional do que os romances ou novelas. Margarida Cardoso, por exemplo, faz o seguinte comentário sobre a questão:

[...] são textos breves, em que a articulação da "tradição" ou da "verdade" com a ficção - difícil escolha da novela histórica - se faz com menos ousadia do que nos romances; limitam-se, com efeito, a dramatizar, com maior ou menor trabalho ficcional, relatos de nosso passado colhidos em obras antigas [...] (CARDOSO, 2003, p.169)

Ofélia Paiva Monteiro tece uma reflexão bastante semelhante sobre o assunto, ela diz que "nesses textos curtos, Herculano quase se limita, por vezes, à dramatização de relatos do nosso passado colhidos em obras antigas” (MONTEIRO, s.d., p.27). Percepção que se alinha ainda com a de Maria de Fátima Marinho ao dizer: "[...] os textos de Lendas e Narrativas [...], na sua maioria, são quase a transcrição de capítulos das crônicas medievais." (MARINHO, 1999, p.54). O problema de qualquer tentativa de apreciação geral da obra reside no fato de ela constituir-se de forma heterogênea, a partir de contos que abarcam diversidades temáticas e estéticas, e cuja extensão varia da forma breve até textos bastante longos, comparáveis, neste quesito, a $O$ bobo ou Eurico.

Na edição das Obras completas do escritor, publicada em 1970, pela Bertrand, tentouse, inclusive, constituir outra disposição que organizasse de modo mais coerente e homogêneo as Lendas e narrativas. Assim, o texto de temática contemporânea, "O pároco de aldeia", passou a fazer parte de um volume autônomo acrescido de outra novela, "O galego", que havia sido publicada apenas nas páginas de A Ilustração. Suprimiu-se também do volume referente às Lendas e narrativas o texto de cunho autobiográfico, "De Jersey a Grandville", que foi anexado ao volume "Cenas de um ano da minha vida".

Desse modo, na nova edição das Lendas e narrativas, "permaneceram as ficções 'históricas' e a novela fantástica, acrescidas de textos ficcionais, de índole idêntica, recuperados dos que o escritor, sem a assinatura ou só com as iniciais de seu nome, publicara n'O Panorama” (MONTEIRO, s.d., p.26). Os textos acrescidos são: "Destruição de Áuria", "O emprazado", "O mestre assassinado", "Mestre Gil", "Três meses em Calecut", "O cronista" e "Os sete dormentes". Lembramos que, da configuração original da obra, permaneceram ainda as seguintes narrativas: "O alcaide de Santarém”, "Arras por foro d'Espanha", "A abóbada", "O bispo negro", "A morte do Lidador" e aquela que talvez possa ser considerada a única narrativa propriamente fantástica na produção de 
Alexandre Herculano: "A Dama Pé-de-Cabra”.

Conforme salientam Ana Márcia Alves Siqueira e Felipe Hélio da Silva Dezidério, é perceptível, nesta narrativa, tanto a inspiração gótica, possivelmente extraída das baladas anteriormente traduzidas pelo autor, como a influência da ambientação lúgubre presente nos textos de Walter Scott, autor assumidamente paradigmático para Herculano:

O escritor, neste conto, usa os procedimentos da escola gótica presentes nas baladas que traduziu e nos recursos descritivos de atmosferas tétricas utilizados por Scott: o castelo e a floresta isolados, as vozes misteriosas, a noite profunda e, principalmente, as lutas e as angústias interiores de seus personagens. (SIQUEIRA; DEZIDÉRIO, 2012, p.70)

Maria Leonor Calixto também relembra a importância de Alexandre Herculano como introdutor de importantes baladas macabras, em Portugal, destacando algumas de suas mais notáveis versões:

[...] trabalhava Herculano nas versões das mais célebres baladas macabras, apresentando, em 1834, Leonor, em 1835 e 36 Affonso e Isolina, em versões diferentes, e ainda $O$ casador feroz e $A$ noiva do sepulcro. Foi igualmente por seu intermédio que Portugal conheceu a balada negra romântica, com O Cavaleiro de Toggenburg [...] (CALIXTO, 1955, p.53)

De modo geral, considerando-se o contexto literário português do período romântico, a pesquisadora destaca Herculano e Castilho como exceções no que diz respeito à prática do romance gótico: "Foram "góticos" o teatro e a balada, mas não o romance, com excepção de Castilho, por vezes Herculano, e pouco mais”. (CALIXTO, 1955, p. 168)

Ainda com relação ao elemento gótico presente nas narrativas de Alexandre Herculano, Calixto, como outros críticos, aponta, particularmente, a prevalência dos componentes sobrenaturais no conto "A Dama Pé-de-Cabra": "O sobrenatural tentou Herculano, que nos deu A Dama Pé-de-Cabra; em O Monge de Cister, é difícil delimitar os processos góticos. São várias as dívidas de Eurico à literatura de terror [...]”(CALIXTO, 1955, p.117).

De fato, tanto as narrativas de Eurico quanto de O Monge de Cister parecem circunscrever a caracterização gótica a dois âmbitos específicos: a ambientação, evidentemente medieval e sombria; e, de modo mais sutil, a passionalidade trágica, excessiva e soturna de seus personagens. Ao abordar os protagonistas das duas narrativas históricas, Maria Leonor Calixto vai enfatizar, precisamente, o modo como o terrífico vai se 
manifestar através da expressão psicológica desses personagens: nas "lutas interiores dos seus heróis, o negro psicológico, as tempestades de paixões exacerbadas, que arrastam Vasco ao crime e Eurico ao desespero.” (CALIXTO, 1955, p.117)

Consideramos, assim, que, embora seja possível identificar elementos fantásticos ou góticos (ou negros ${ }^{2}$, de acordo com a terminologia usada por Calixto) em alguns textos ficcionais de Alexandre Herculano, na maioria dos casos, tais fatores parecem limitados a contextos específicos, não contemplando o desenrolar geral da narrativa. Em "A Dama Péde-Cabra", no entanto, o fantástico assume uma expressão mais abrangente, caracterizando não apenas a figura central do conto, e situações específicas relacionadas a ela, mas perpassando também o conteúdo narrativo geral.

Os elementos fantásticos que compõem o conto originam-se da configuração sobrenatural da personagem, que dá título à narrativa, mas, como veremos a seguir, tal expressão de periculosidade será confrontada, ao longo do texto, com outro tipo de ameaça advinda da presença de um elemento invasor, os mouros. Tal disposição viabiliza instigantes reflexões acerca dos dois tipos de ameaça abordados: o sobrenatural e o bélico de fundo histórico. $\mathrm{Na}$ medida em que alguns personagens vivenciam tanto os riscos referentes à presença fantástica e demoníaca da Dama, como, ainda, aqueles relativos às lutas contra os mouros, é possível estabelecer uma analogia que relativize a importância de uma ameaça em relação à outra. Em alguns momentos, conforme veremos adiante, ocorre, inclusive, a neutralização de um dos perigos pela atuação do outro. Tentaremos sintetizar, a seguir, os principais fatos que compõem a trama narrativa para depois retomarmos, de forma mais consistente, as reflexões aqui iniciadas.

Embora se trate de uma trama relativamente simples a organização narrativa é o que de fato constitui a complexidade do texto, perfazendo-se assim imbricadas relações entre os diversos contextos aí abarcados. Conforme salienta Ofélia Paiva Monteiro, a lenda foi desenvolvida "em vários níveis narrativos, que implicam uma curiosa estruturação temporal [...]”. (MONTEIRO, s.d., p.27)

\footnotetext{
2 Em lugar de gótico, Maria Leonor Calixto utiliza o termo negro, assim explicando sua escolha: “o termo negro que escolhi para designar toda esta literatura desenrolada num ambiente de terror, é o que me pareceu mais adequado. Gótico, talvez mais clássico, embora legítimo quando empregado para a fase inicial da escola, não tem hoje significação, quando aplicado ao campo da literatura atual que se pode considerar descendente do 'horror gótico'. O traço comum é o seu ambiente sombrio, e daí a classificação: no seu sentido mais lato, 'negro' é uma designação de ambiente, e nada mais." (CALIXTO, 1955, p.11)
} 


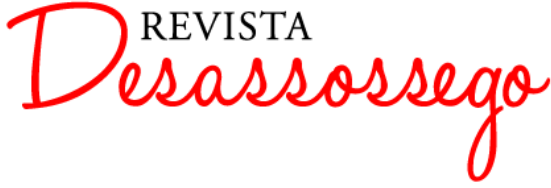

A principal referência ao tempo histórico remete à época da ocupação muçulmana na Espanha, apresentando-se, mais especificamente, o XI século. É interessante observar que, ao contrário de outras obras de Alexandre Herculano, a representação dos mouros, nesse conto, manifesta-se, aparentemente, como elemento de fundo, constitutivo de parte do contexto histórico aí contemplado.

A trama, bastante conhecida, inicia-se com a união entre D. Diogo Lopes, senhor de Biscaia, e certa dama que ele encontrara em uma penha, localizada na fronteira de suas terras. Depois que tiveram dois filhos, D. Inigo Guerra e D. Sol, confirma-se parte de um mistério que vinha sendo prenunciado: a natureza assombrosa e diabólica da mulher de D. Diogo. Certo dia, ao ver o seu cachorro ser morto pela cadela, que pertencia a sua esposa, o senhor de Biscaia quebra o juramento feito a ela, de nunca se benzer, e decorre então a seguinte cena:

Ui! - gritou sua mulher, como se a houveram queimado. O barão olhou para ela: viu-a com os olhos brilhantes, as faces negras, a boca torcida e os cabelos eriçados:

E ia-se alevantando, alevantando ao ar, com a pobre D. Sol sobraçada debaixo do braço esquerdo: o direito estendia-o por cima da mesa para seu filho, D. Inigo de Biscaia.

E aquele braço crescia, alongando-se para o mesquinho, que, de medo, não ousava bulir nem falar.

E a mão da dama era preta e luzidia, como o pelo da podenga, e as unhas tinham-se-lhe estendido bem meio palmo e recurvado em garras. (HERCULANO, 1987, p.119)

Passa-se, assim, para a segunda trova, na qual se fica sabendo que D. Diogo Lopes está agora cativo dos mouros e que seu filho, já adulto, quer salvá-lo. Aconselhando-se sobre o assunto com o pajem, Brearte, D. Inigo acaba contando-lhe outra história, referente à origem de sua mãe, a Dama Pé-de-Cabra. Narra-se, assim, a lenda do Conde Argimiro, o Negro, e Astrigildo Alvo. Argimiro, que ficara dois anos em Toledo, lutando nas guerras do Rei de Wamba, ao voltar pra casa descobre o adultério da condessa, sua esposa, assassinando-a, por este motivo, junto com o seu amante Astrigildo.

O episódio é descrito com elementos fantásticos e representa, na verdade, a punição à quebra de uma promessa feita por Argimiro ao seu pai, de nunca matar "fera em cama e com cria" (HERCULANO, 1987, p.124). A mulher morta em estado de adultério seria, assim, a própria Dama que, centenas de anos depois, D. Diogo viria a encontrar nas penhas. Seu amante, Astrigildo, transformado em um ónagro, será também retratado 
posteriormente, na história referente à D. Diogo e seu filho: "Desde esse tempo, as duas miseráveis almas têm aparecido a muita gente nos desvios de Biscaia: ela vestida de branco e vermelho, assentada nas penhas, cantando lindas toadas; ele retouçando aí perto, na figura de um ónagro.” (HERCULANO, 1987, p.130)

A referência ao Rei de Wamba, naquela passagem, revela um importante elemento temporal do texto, pois, considerado o último rei godo, esse personagem histórico teria vivido no VII século. Assim, entre o plano narrativo concernente à história de D. Diogo Lopes e aquele, relativo à origem da Dama Pé-de-Cabra, há uma diferença temporal de aproximadamente quatro séculos.

Prosseguindo a trama narrativa, D. Inigo Guerra, aconselhado por Brearte, decide procurar sua mãe para pedir que o auxilie a salvar D. Diogo do cativeiro mouro em Toledo. Assim, em cenas permeadas por fatos sobrenaturais, a Dama e um certo ónagro, que seria a representação de Astrigildo, ajudam a resgatar o pai de D. Inigo. Ao fim da narrativa, falase da proximidade estabelecida entre D. Inigo Guerra e sua mãe, a Dama Pé-de-Cabra, insinuando-se, também, um pacto com belzebu e a existência de vários outros mistérios ocorridos no castelo depois de sua morte, que não foram retratados na narrativa.

D. Diogo pouco tempo viveu: todos os dias ouvia a missa; todas as semanas se confessava. D. Inigo, porém, nunca mais entrou na igreja, nunca mais rezou, e não fazia senão ir à serra caçar.

Quando tinha de partir para as guerras de Leão, viam-no subir à montanha armado de todas as peças e voltar de lá montado num agigantado ónagro.

E o seu nome retumbou em toda a Espanha; porque não houve batalha em que entrasse que se perdesse, e nunca em nenhum encontro foi ferido nem derribado.

Diziam à boca pequena em Nustúrio que o ilustre barão tinha pacto com Belzebu. Olhem que era grande milagre!

Meio precito era ele por sua mãe; não tinha que vender senão a outra metade da alma. (HERCULANO, 1987, P.145)

Helena Carvalhão Buescu, considerando a possibilidade de entendimento de $A$ Dama Pé-de-Cabra "como narrativa alegórica, funcionando ao modo de uma parábola construída sobre um gesto metafórico" (BUESCU, 2005, p.88), elabora uma análise bastante interessante do conto. A autora orienta-se, entre outros parâmetros, pela relação entre predação e domesticidade, extraída da temática do caçador caçado, implicada na narrativa. 
Lembramos que tanto D. Diogo Lopes quanto o Conde Argimiro são caçadores de animais e também de pessoas. Em ocasiões diferentes, o primeiro parte para as disputas em Toledo, para caçar mouros, e o segundo vai para a Guerra do Rei de Wamba. Mas, ambos teriam sido também, de algum modo, caçados pela mesma mulher, que os levaria à ruína e perdição e, ainda, por suas próprias caças, conforme veremos adiante.

Há que se considerar o espelhamento entre a motivação primeira das desgraças, que se abateram sobre Argimiro e sobre D. Diogo, e das respectivas consequências desses eventos. Argimiro descumpre a promessa feita ao seu pai, de nunca matar "fera em cama e com cria" (HERCULANO, 1987, p.124), e tal atitude tem como resultado o retorno fantástico do ónagro, levando a Condessa ao adultério e seu marido à desonra e perdição. D. Diogo Lopes, de certa forma, quebra um vínculo religioso (de benzer-se), substituindoo pela promessa de "caçar mouros", mas, ao invés disso, torna-se prisioneiro dos muçulmanos, em Toledo. Em ambos os casos, os caçadores foram arruinados, exatamente, por exercerem de forma prepotente o ato da caça, colocando-a acima de um compromisso moral. A consequência final de seus excessos e arrogância é que eles acabam sendo vítimas de suas próprias caças.

Assim, aproveitando as reflexões suscitadas pelo artigo de Buescu, principalmente no que se refere à questão da dimensão alegórica do conto e da temática da domesticidade aí ressaltada, encontramos também, tangencialmente a essa proposta, um aspecto relevante contido na estruturação narrativa: a alternância entre a periculosidade advinda do contexto interno, ou doméstico, e do externo, ou estrangeiro.

A figura feminina, representada pela Dama Pé-de-Cabra, na história de D. Diogo Lopes, e pela Condessa de Biscaia, do século VII, no episódio referente ao Conde Argimiro, estaria, a princípio, circunscrita ao espaço interno ou doméstico. Lembramos que, embora exerçam o papel de predadoras, é exatamente no âmbito caseiro que elas realizam as ações, que vão fomentar o processo de ruína dos seus pares: o adultério da Condessa de Biscaia e a transformação assombrosa da Dama em uma figura demoníaca. Por outro lado, D. Diogo Lopes, D. Inigo Guerra e Argimiro, que seriam as figuras masculinas de maior destaque na narrativa, além do âmbito doméstico, transitam, também, pelo espaço externo, participando, os dois primeiros, como foi visto, das guerras contra os mouros, e o Conde Argimiro, quatro séculos antes, lutando contra rebeliões contrárias ao rei de Wamba, também na região de Toledo. 


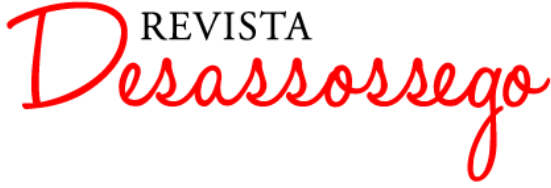

A presença moura no conto parece, mesmo, pontuar passagens importantes da lenda referente a D. Diogo Lopes e ao seu filho, D. Inigo Guerra. Conforme mencionamos anteriormente, D. Diogo, ao prometer à Dama que nunca mais faria o sinal da cruz, apresenta, como compensação à falta religiosa, a possibilidade de matar um grande número de mouros, como disposto a seguir: "De que servem benzeduras? Matarei mais duzentos mouros e darei uma herdade a Santiago. Ela por ela. Um presente ao apóstolo e duzentas cabeças de cães de Mafamede valem bem um grosso pecado.” (HERCULANO, 1987, p.117). Depois, quando ocorre o episódio assombroso da transformação de sua mulher, D. Diogo, tentando se refazer da desgraça sofrida, decide ir a Toledo "caçar mouros":

D. Diogo Lopes viveu muito tempo triste e aborrido, porque já não se atrevia a montear. Lembrou-se, porém, um dia de espairecer sua tristura, e, em vez de ir à caça dos cerdos, ursos e zebras, sair à caça de mouros. (HERCULANO, 1987, p.120).

E, finalmente, ele acaba sendo aprisionado pelos mouros, e é por esse motivo que D. Inigo Guerra, com intento de salvá-lo, procura sua mãe. É interessante observar, nesse ponto, que, o perigo interno, representado pela Dama, acaba sendo utilizado para revogar o perigo externo, que seria o cativeiro mouro, no qual se encontra D. Diogo Lopes. Através dos encantamentos urdidos pela Dama, D. Inigo consegue resgatar seu pai do poderio dos mouros.

Já a história de Argimiro é, de certa forma, determinada pela luta contra os estrangeiros, pois é pela necessidade de ir para Toledo lutar pelo Rei de Wamba, que ele se ausenta de sua casa e, ao retornar, descobre a traição da esposa.

Percebe-se, assim, que a ação narrativa é movida pela alternância entre um perigo externo, representado pelos estrangeiros, sejam eles mouros ou apenas invasores vindos de outras regiões da Europa, e pela ameaça interna, representada nos dois casos pela mesma figura feminina. A ameaça externa relaciona-se aos fatos históricos ocorridos na península Ibérica, mas é no componente interno e doméstico que residem as questões mais assombrosas, elaboradas na narrativa com elementos fantásticos. É importante ressaltar que, a personagem da Dama Pé-de-Cabra, elaborada por Alexandre Herculano, cuja lenda teria sido extraída do livro de Linhagens do Conde D. Pedro (MONTEIRO, s.d., p.27), não tem realmente nenhuma herança familiar moura, conforme é enfatizado no seguinte excerto da narrativa: 
De nunca dar tréguas à mourisma, nem perdoar aos cães de Mafamede? Sou bom cristão. Guai de ti e de mim, se és dessa raça danada! Não é isso, dom cavaleiro - interrompeu a donzela a rir. (HERCULANO, 1987, p.117)

Lembramos ainda que, se na lenda original do livro de linhagens não há nenhuma referência a esse assunto, em algumas lendas populares, entretanto, as mouras são apresentadas com os pés de cabras, como é o caso da lenda da "Torre de Dona Chama", que tem como figura principal uma princesa moura com pernas de cabra (PARAFITA, 2006, p.85). Assim, identificamos na citação acima uma opção, não arbitrária, por manter essa personagem tão misteriosa, com traços certamente demoníacos, como um fruto apenas da alta linhagem da família ibérica. É a própria Dama, quem afirma a D. Diogo Lopes: "Sou de tão alta linhagem como tu; porque venho do semel de reis, como tu, senhor de Biscaia." (HERCULANO, 1987, p.116). Apreendemos aqui uma dimensão ainda mais ampla para o contexto de domesticidade ao qual associamos a figura da Dama. Se, como afirmamos anteriormente, é no espaço doméstico, em um jantar familiar, que ela revela sua natureza assombrosa, tal natureza não está, de forma alguma, vinculada a qualquer herança mourisca ou estrangeira. Desse modo, a domesticidade concernente à Dama, diz respeito também à evidenciação, apresentada na narrativa, de sua origem nacional ou ibérica.

Os mouros, reificados como uma caça, pouco mais importante que cerdos e ursos, funcionam, em um primeiro momento, como forma de remissão para a culpa de D. Diogo pelo casamento com a Dama. Depois, em um movimento circular, como vimos, é exatamente a intervenção da Dama Pé-de-Cabra que define o salvamento de D. Diogo Lopes do cativeiro mouro ao qual ele foi submetido, em Toledo. Assim, os perigos externos, representados pelos mouros ou outros estrangeiros, parecem, de fato, convergir para uma força maior, localizada em um âmbito interior, que seria a um tempo a origem mesmo desses perigos, mas também a possibilidade de sua solução.

Delineia-se, dessa forma, no conto de Alexandre Herculano, uma oscilação entre a longínqua periculosidade externa, representada pelos muçulmanos, e o perigo interno mais premente e constante associado à assombrosa figura feminina da Dama. Como vimos, a questão principal é endógena e diz respeito aos problemas domésticos ou nacionais, que poderiam associar-se a um lado obscuro da alta linhagem ibérica, à qual pertence a Dama. Os mouros e outros estrangeiros são aí referidos apenas como elementos adjacentes a essa 
trama, funcionando como instrumento de remissão para os erros ou pecados cometidos no âmbito interno, sendo a sua derrota e morte, por exemplo, objeto de barganha religiosa. É importante lembrar aquelas palavras, já mencionadas, de D. Diogo Lopes, sobre o escambo das benzeduras pelas cabeças de mouros, para evidenciar a instrumentalização à qual referimos.

Observamos finalmente que, enquanto a Guerra do Rei de Wamba e a ocupação moura em Toledo foram sinteticamente traçadas com características históricas realistas, a periculosidade interna, associada, como vimos, ao contexto ibérico, foi elaborada com elementos assombrosos e sobrenaturais. Tal configuração fantástica poderia significar, em uma vertente interpretativa alegórica, a crítica denunciadora dos problemas endógenos em detrimento dos conflitos externos. Afinal, é a recorrência de um mesmo problema doméstico, traçado com elementos fantásticos e assombrosos, o que constitui, de fato, os principais conflitos presentes à narrativa.

\section{REFERÊNCIAS BIBLIOGRÁFICAS}

ALBUQUERQUE, M. Fátima. A obra novelística de Alexandre Herculano. In: Actas do Colóquio Alexandre Herculano liberalismo e romantismo. Escola Superior de Educação de Santarém: Santarém,1999.

BUESCU, Helena Carvalhão. 2005. A obra literária de Alexandre Herculano. In: AFONSO, Graça; MATOS, Álvaro Costa. Alexandre Herculano: um pensamento "poliédrico". Colóquio Comemorativo dos 120 anos de sua morte (1877 - 1997). Coleção: Actas \& Colóquios da Hemeroteca, $n^{\circ}$ 3. Bibliotecas Municipais de Lisboa: Lisboa, 2005. p.151 162.

CALIXTO, Maria Leonor. A literatura "negra" on de "terror" em Portugal nos séculos XVIII e XIX. Publicações da Faculdade de Letras da Universidade de Lisboa: Lisboa, 1955.

CARDOSO, Margarida. Alexandre Herculano. In: MACHADO, Álvaro Manuel et al. História da Literatura Portuguesa. Lisboa: Publicações Alfa, 2003. p.141 - 185.

HERCULANO, Alexandre. Lendas e narrativas. Lisboa: Editorial Comunicação, 1987.

HERCULANO, Alexandre. Lendas e narrativas. Amadora: Bertrand, 19--.

MARINHO, Maria de Fátima. O Romance Histórico em Portugal. Porto: Campos das Letras, 1999. 
MONTEIRO, Ofélia Paiva. Romantismo e Romantismos. In: CASTRO, Francisco Lyon (Ed.). História da Literatura Portuguesa. Lisboa: Publicações Alfa, 2003. p. 9 - 43.

PARAFITA, Alexandre. A Mitologia dos Mouros. Canelas: Gailivro, 2006.

SIQUEIRA, Ana Márcia Alves; DEZIDÉRIO, Felipe Hélio da Silva. "A face negra de Alexandre Herculano: visões históricas do mal na construção do sobrenatural em 'A Dama Pé de Cabra". Revista do Núcleo de Estudos de Literatura Portuguesa e Africana da UFF. NEPA/UFF, Niterói, Vol. 4, nº 8, Abril de 2012. p. 67 - 84.

Artigo recebido em 15 de abril de 2014

Artigo aceito em 09 de junho de 2014 